\title{
CIP2A regulates MYC translation (via its 5'UTR) in colorectal cancer
}

\author{
S. Denk ${ }^{1,2} \cdot$ S. Schmidt ${ }^{1,2} \cdot$ Y. Schurr $^{1} \cdot$ G. Schwarz ${ }^{1} \cdot$ F. Schote ${ }^{1} \cdot$ M. Diefenbacher ${ }^{1} \cdot$ C. Armendariz $^{1} \cdot$ F. Dejure $^{1} \cdot$ \\ M. Eilers ${ }^{1,3} \cdot$ Armin Wiegering $^{1,2,3}$ [1]
}

Accepted: 7 October 2020 / Published online: 19 October 2020

(C) The Author(s) 2021

\begin{abstract}
Background Deregulated expression of MYC is a driver of colorectal carcinogenesis, suggesting that decreasing MYC expression may have significant therapeutic value. CIP2A is an oncogenic factor that regulates MYC expression. CIP2A is overexpressed in colorectal cancer (CRC), and its expression levels are an independent marker for long-term outcome of CRC. Previous studies suggested that CIP2A controls MYC protein expression on a post-transcriptional level.

Methods To determine the mechanism by which CIP2A regulates MYC in CRC, we dissected MYC translation and stability dependent on CIP2A in CRC cell lines.

Results Knockdown of CIP2A reduced MYC protein levels without influencing MYC stability in CRC cell lines. Interfering with proteasomal degradation of MYC by usage of FBXW7-deficient cells or treatment with the proteasome inhibitor MG132 did not rescue the effect of CIP2A depletion on MYC protein levels. Whereas CIP2A knockdown had marginal influence on global protein synthesis, we could demonstrate that, by using different reporter constructs and cells expressing MYC mRNA with or without flanking UTR, CIP2A regulates MYC translation. This interaction is mainly conducted by the MYC 5'UTR.

Conclusions Thus, instead of targeting MYC protein stability as reported for other tissue types before, CIP2A specifically regulates MYC mRNA translation in CRC but has only slight effects on global mRNA translation. In conclusion, we propose as novel mechanism that CIP2A regulates MYC on a translational level rather than affecting MYC protein stability in CRC.
\end{abstract}

Keywords CIP2A $\cdot$ MYC $\cdot$ Translation $\cdot$ Colon cancer

\section{Introduction}

With more than 1.2 million newly diagnosed cases per year, colorectal cancer (CRC) is the most common gastrointestinal malignancy [1]. Sequence analysis shows that each tumor genome carries multiple mutations deregulating major signaling pathways that control growth and survival of colon epithelial

Electronic supplementary material The online version of this article (https://doi.org/10.1007/s00384-020-03772-y) contains supplementary material, which is available to authorized users.

Armin Wiegering

wiegering_a@ukw.de

1 Department of Biochemistry and Molecular Biology, Biocenter, University of Würzburg, Würzburg, Germany

2 Department of General, Visceral, Transplant, Vascular and Pediatric Surgery (Department of Surgery I), University Hospital Würzburg, Oberduerrbacherstr. 6, 97080 Würzburg, Germany

3 Comprehensive Cancer Center Mainfranken, University of Würzburg, Würzburg, Germany cells [2]. Despite the genomic heterogeneity, enhanced MYC expression is universally observed in colon cancers. Gene expression analyses show that a signature of activated and repressed MYC target genes is present in a vast majority of CRC [2]. Deletion of the MYC gene ablates tumorigenesis in mouse models that faithfully mimic the human disease [3]. Collectively, these data argue that targeting MYC might achieve significant therapeutic efficacy in CRC.

Besides its transcriptional overexpression, MYC mRNA translation and stability are enhanced in cancer [4]. One major post-transcriptional regulator of MYC protein is the cancerous inhibitor of protein phosphatase 2A (CIP2A), which was identified as a human oncoprotein [5]. CIP2A is overexpressed in human tumor entities including CRC, gastric cancer, head and neck squamous cell carcinoma, breast cancer, prostate cancer, and lymphoma [6-8]. Enhanced expression of CIP2A correlates with reduced survival and serves as an independent negative predictive marker for overall and disease-free survival [9-14]. Several exogenous cancer-inducing factors, like Helicobacter pylori and papilloma virus $16 \mathrm{E} 7$, upregulate the expression of 
CIP2A in host tissue which may be critical for their oncogenic activity $[15,16]$.

Consistent with CIP2A's role as an inhibitor of the ubiquitous serine/threonine phosphatase PP2A which regulates the activity of numerous cellular signaling pathways [17], CIP2A has been shown to regulate the phosphorylation and activity of AKT, DapK, E2F1, MYC, and mTORC [13, 18, 19]. We and others have shown that on a molecular level, CIP2A regulates MYC post-transcriptionally due to several mechanisms. First, PP2A has a critical role in the turnover of MYC, since PP2A dephosphorylates MYC at serine 62 (S62). Dephosphorylation at $\mathrm{S} 62$ is required for ubiquitination of $\mathrm{MYC}$ by the ubiquitin ligase FBXW7 and therefore initiates degradation of MYC [6, 7]. Overexpression of CIP2A inhibits PP2A activity and thereby leads to MYC stabilization. Second, it has been shown that CIP2A specifically stabilizes pS62-MYC by interaction with the Lamin A/C complex in the nucleus [20]. Consequently, overexpression of CIP2A induces immortalization and malignant transformation of human cells.

Here, we show that CIP2A regulates MYC protein expression post-transcriptionally in $\mathrm{CRC}$ and that this regulation occurs via MYC mRNA translation rather than MYC stability.

\section{Results}

To analyze the impact of CIP2A on MYC protein expression and to recapitulate already published data in the setting of CRC, CIP2A expression was downregulated via siRNA in three CRC cell lines (HCT116, SW480, and LS174t). CIP2A knockdown led to substantial reductions in MYC protein levels in all three cell lines (Fig. 1a). This was due to posttranscriptional regulation of MYC protein levels, as no changes in $M Y C$ mRNA expression were detected (Fig. 1b). To rule out off-target effects of the used siRNA pool, HCT116 cells were transfected with three independent siRNAs side-by-side. Two of the three tested siRNAs led to a strong downregulation of CIP2A on mRNA and protein level as well as a reduced expression of MYC on protein, but not on mRNA level (Supplementary Fig. 1A, B). In contrast, one siRNA (\#2) only leads to a slight knockdown of CIP2A and does not reduce $\mathrm{MYC}$ protein expression. In conclusion, this data argues that knockdown of CIP2A regulates MYC on protein level.

To determine long-term effects of CIP2A depletion on cell proliferation, HCT116 cells were stably infected with an shRNA targeting CIP2A. shRNA-mediated knockdown of CIP2A led to a growth defect in these cells, furthermore validating the results of siRNA-mediated depletion of CIP2A (Fig. 1c, d). Flow cytometry analysis (FACS) of propidium-iodide stained cells upon CIP2A knockdown revealed an accumulation of cells in G1 phase of the cell cycle, but the subG1 phase remained unaltered (Fig. 1e, f). This is comparable to a cell cycle arrest observed after reduction of MYC levels in other settings [21-23]. To validate the overexpression of CIP2A in CRC, we analyzed expression data in $275 \mathrm{CRC}$ and 41 mucosa samples from ciBioPortal (https://www.cbioportal.org). This clearly demonstrated a strong upregulation of CIP2A in cancer tissue (Fig. 1g).

In many cell lines, MYC proteins turn over with a half-life of approximately $20 \mathrm{~min}$ [24]. To determine the stability of MYC in CRC cell lines dependent on CIP2A, we treated cells with cycloheximide to inhibit new protein synthesis and measured the amount of remaining MYC protein by immunoblotting at several time points after treatment (Fig. 2a-c). MYC turned over with a half-life of approximately $30 \mathrm{~min}$ in all three CRC cell lines. Surprisingly, knockdown of CIP2A by siRNA did not affect MYC protein stability in any of the cell lines (Fig. 2a-c).

MYC stability and phosphorylation is regulated by growth factor-dependent ERK and PI3K signaling pathways. Phosphorylation of MYC at serine 62 by ERK is necessary for recognition and subsequent phosphorylation at threonine 58 by GSK3 $\beta$. Phosphorylated T58 is recognized by PIN1, as prerequisite for PP2A-dependent dephosphorylation of MYC proteins at S62 [4, 25, 26]. MYC protein, exclusively phosphorylated at $\mathrm{T} 58$, is recognized and ubiquitinated by SCF-FBXW7 and thereby primed for proteasomal degradation [4]. If CIP2A does not influence MYC protein stability, as suggested by the results of the cycloheximide assay, knockdown of CIP2A should still reduce MYC protein levels even if protein degradation is blocked. To evaluate the impact of CIP2A-dependent MYC expression and FBXW7-dependent MYC degradation, CIP2A expression was downregulated via siRNA transfection in both HCT116 $\mathrm{FBXW}^{+/+}$and HCT116 FBXW7 $^{-1-}$ cells (Fig. 3a). As expected, FBXW7-deficient cells showed per se higher MYC protein levels compared to FBXW7-proficient cells. Knockdown of CIP2A led to a comparable reduction of $\mathrm{MYC}$ protein in both conditions. To rule out the possibility that CIP2A primes MYC for another ubiquitin E3 ligase, overall protein degradation was inhibited by treating cells with the proteasome inhibitor MG132. MG132 treatment led to an expected accumulation of MYC and, to a lower extent, of CIP2A (Fig. 3b). In both MG132-treated and untreated cells, knockdown of CIP2A led to a comparable downregulation of MYC protein levels (Fig. 3b). In conclusion, our data suggest that CIP2A does affect neither MYC transcription nor MYC protein stability in CRC, but that CIP2A rather influences translation of MYC.

To test whether CIP2A has an impact on global protein synthesis, HCT116 cells were starved for $20 \mathrm{~min}$ in methionine-free media. After that, incorporation of $\mathrm{S}^{35}$-labeled methionine within $1 \mathrm{~h}$ was measured (Fig. 3c). Knockdown of CIP2A did not show any effect on global protein synthesis. To clarify whether CIP2A directly influences MYC translation, a reporter plasmid, carrying the 
a

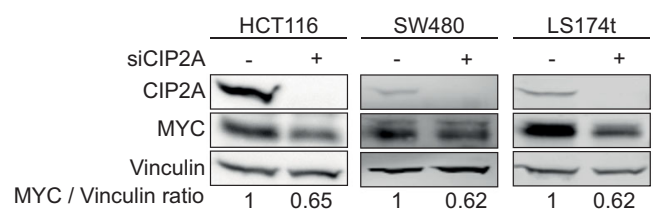

C

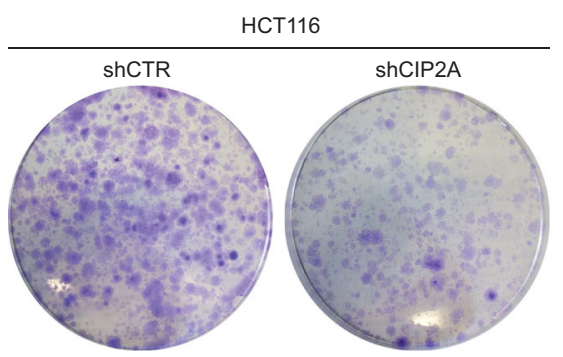

e

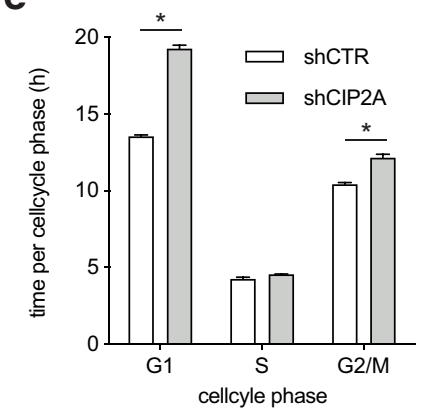

f b

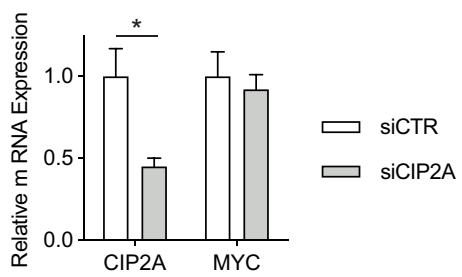

d

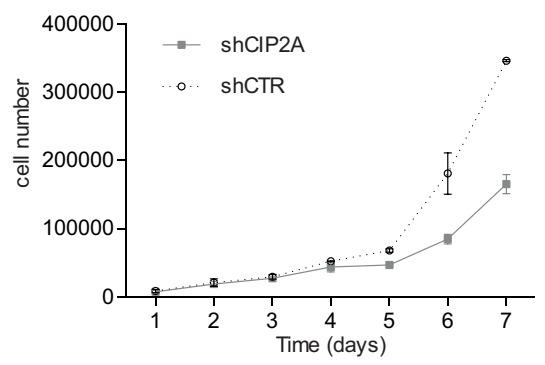

g

Fig. 1 Depletion of CIP2A regulates MYC protein and cell proliferation in CRC cell lines. a Western blot analysis of CIP2A and MYC protein expression in HCT116, SW480, and LS174t cells transfected with CIP2A or CTR siRNA for $72 \mathrm{~h}$. Data are representative of three independent experiments. b RT-QPCR analysis of CIP2A and MYC mRNA expression in HCT116 $72 \mathrm{~h}$ after transfection with siRNA targeting CIP2A (mean of three independent biological experiments, error bars represent +/- SD). c Crystal violet staining of HCT116 cells stably infected with CIP2A or CTR shRNA after 7 days in culture. d Cell number of HCT116

$M Y C 5^{\prime} \mathrm{UTR}$ ahead of the coding sequence of a firefly luciferase (pmF), was used. Knockdown of CIP2A led to a $60 \%$ decrease in relative luciferase activity, pointing towards a direct influence of CIP2A on MYC translation (Fig. 3d). To test whether CIP2A knockdown affects the translation from other structured 5'UTRs, we used bicistronic vectors containing the IRES element of the EMCV or HCV virus. In both conditions, knockdown of CIP2A does not alter luciferase activity (Fig. 3e). In summary, we concluded that CIP2A regulates MYC on a translational level in CRC.

mRNA translation can be regulated by several upstream pathways, e.g., mTOR signaling, or via direct regulation of translation initiation or elongation factors [27]. We have previously shown that CIP2A does not regulate mTOR signaling in CRC [7]. To evaluate whether CIP2A affects MYC
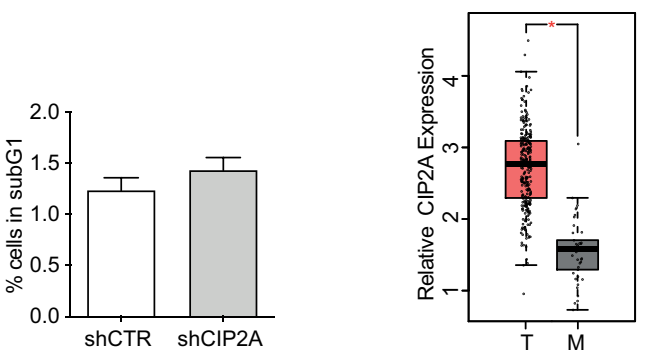

cells stably infected with CIP2A or CTR shRNA during 7 days in culture (mean of three independent biological experiments, error bars represent +/- SD). e Time per cell cycle phase of HCT116 cells after CIP2A knockdown $(* p<0.001)$ (mean of three independent biological experiments, error bars represent $+/-\mathrm{SD}$ ). $\mathbf{f}$ Fraction of cells in subG1 phase after knockdown of CIP2A (mean of three independent biological experiments, error bars represent $+-\mathrm{SD}$ ). $\mathrm{g}$ Expression of CIP2A in CRC (T) or corresponding mucosa $(\mathrm{M})(* p<0.01)$

translation initiation or elongation, we used HCT116 cells with doxycycline-inducible MYC constructs expressing the MYC coding sequence (CDS) with or without $5^{\prime} / 3^{\prime}$ UTRs with an HA-tag to distinguish between endogenous and exogenous MYC [22, 28] (Fig. 4a). Whereas endogenous MYC protein was reduced by CIP2A knockdown, MYC constructs expressing the MYC CDS or MYC CDS + 3'UTR remained mainly unaffected by CIP2A knockdown (Fig. 4b). However, the construct expressing the MYC CDS + 5'UTR was robustly downregulated to a ratio of 0.66 after CIP2A knockdown. The most prominent effect on MYC protein reduction after CIP2A knockdown was observed with the construct expressing the MYC 5'UTR + CDS + 3'UTR (ratio of 0.39, Fig. 4b). In conclusion, these data show that CIP2A regulates MYC translation initiation rather than elongation, as the expression of the MYC CDS is unaffected. 

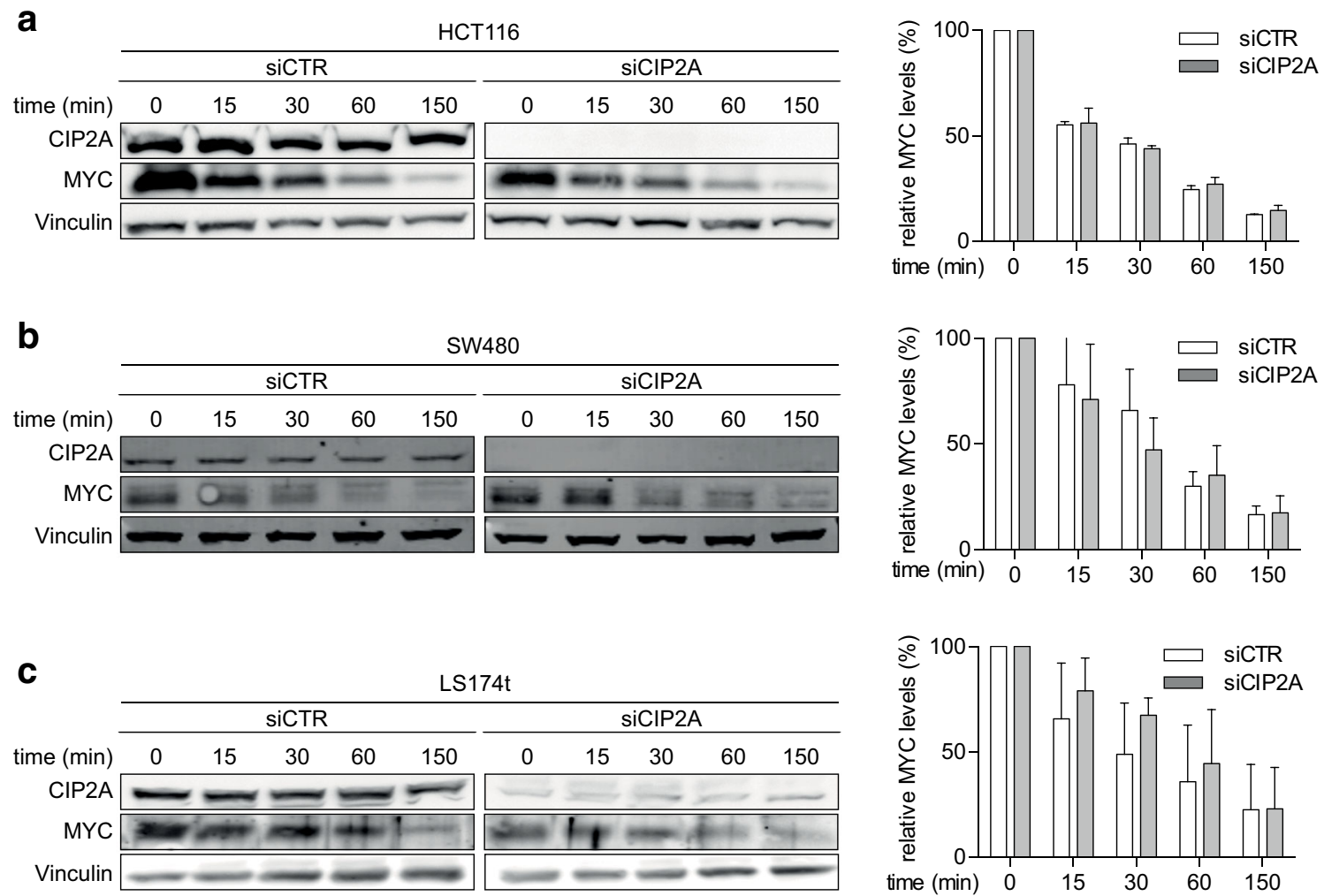

Fig. 2 Depletion of CIP2A does not alter MYC protein stability in CRC cells. Immunoblots documenting MYC protein stability. Cells were incubated with cycloheximide $(50 \mu \mathrm{g} / \mathrm{ml})$ for the indicated time. a HCT116 left panel, immunoblot; right panel, quantification of MYC to vinculin ratio. b SW480 left panel, immunoblot; right panel,

\section{Discussion}

Deregulated and enhanced expression of MYC is a driver of colorectal tumorigenesis, necessitating strategies to inhibit MYC function or expression for tumor therapy. We and others have shown that CIP2A regulates MYC, is essential for tumor growth, tissue regeneration, and thus may open a therapeutic window for targeting tumors $[6,7,10,18,20,29]$.

It has been clearly demonstrated that CIP2A reduces MYC expression post-transcriptionally. For example, mouse embryonic fibroblasts (MEF) isolated from CIP2A-deficient $\left(\mathrm{CIP} 2 \mathrm{~A}^{\mathrm{HOZ}}\right)$ mice show the same amount of $M Y C$ mRNA as wild-type mice, but harbor lower MYC protein levels after serum stimulation [20]. In line with this are our own published results that CIP2A does not influence MYC mRNA expression arguing that $\mathrm{MYC}$ is regulated post-transcriptionally by CIP2A [7]. So far, on a molecular level, it was shown that CIP2A regulates the stability of MYC, mainly by stabilizing pS62-MYC. Here, we describe a novel mechanism of regulation of MYC translation by the oncoprotein CIP2A via the $5^{\prime}$ UTR of the MYC mRNA. It remains elusive which factor drives MYC translation in tumors and is regulated by CIP2A. Still, our experiments showing that MG132 treatment does not rescue downregulation of MYC protein upon CIP2A quantification of MYC to vinculin ratio. c LS174t left panel, immunoblot; right panel, quantification of MYC to vinculin ratio. Immunoblots are representative of three independent experiments. Quantifications show mean of three independent biological experiments; error bars represent +/- SD

knockdown clearly argue against a regulation of MYC stability by CIP2A in CRC.

There are several possibilities how MYC translation can be regulated via CIP2A. First, PP2A can mediate regulation of upstream pathways like mTOR signaling which has been proposed previously [30]. This is unlikely for CRC, as we have already demonstrated that $\mathrm{PI} 3 \mathrm{~K} / \mathrm{AKT} / \mathrm{mTOR}$ signaling is not affected by CIP2A [7]. Second, CIP2A could directly regulate the function or activity of translation factors. The process of mRNA translation is divided in three regulatory parts, initiation, elongation, and termination [27]. Regarding elongation, our experiments do not show an effect on MYC CDS expression after CIP2A depletion, arguing that CIP2A does not act via the regulation of elongation of the MYC mRNA. In contrast, CIP2A influences the 5'UTR of MYC as demonstrated in our experiments by regulation of firefly luciferase expression as well as exogenous constructs carrying MYC CDS $+5^{\prime}$ UTR. Whereas global protein synthesis is unaltered or only slightly reduced, which could be explained by the reduced MYC protein levels and cell proliferation, the firefly luciferase activity and MYC protein levels are decreased to a much greater extent. These results strongly support the notion that CIP2A regulates MYC translation initiation. Several oncogenes, like $M Y C, S R C$, and $V E G F$, harbor complex structures 
a

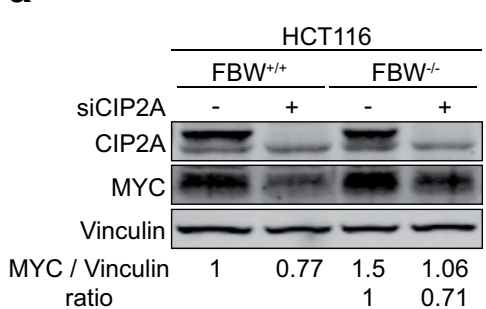

b

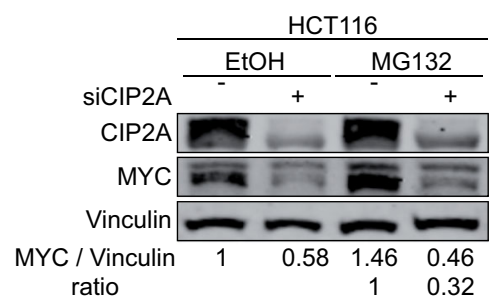

C

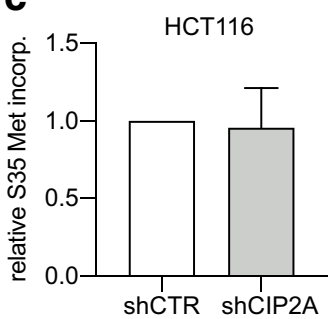

d
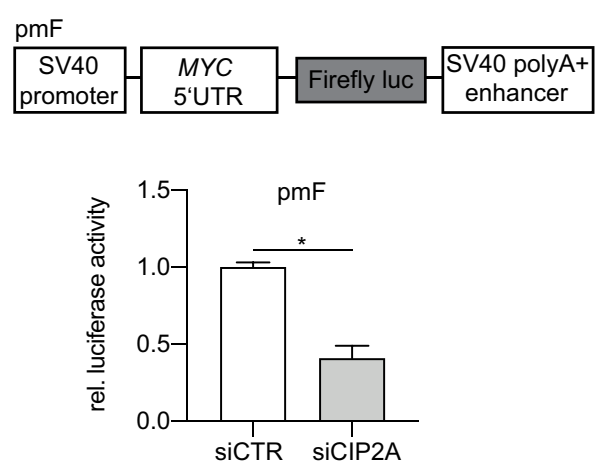

Fig. 3 Inhibition of proteasomal degradation does not rescue MYC protein expression after CIP2A knockdown. a Western blot analysis of CIP2A and MYC protein expression in FBXW7-proficient $\left(\mathrm{FBXW}^{+/+}\right.$) and -deficient $\left(\mathrm{FBXW7^{-/ }}{ }^{-}\right.$) HCT116 cells. Data are representative of three independent experiments. b Western blot analysis of CIP2A and MYC protein expression in HCT116 cells treated with the proteasomal inhibitor MG132 $(50 \mu \mathrm{g} / \mathrm{ml})$ or solvent control (ETOH). Data are representative of three independent experiments. c Incorporation of S35labeled methionine in HCT116 cells after knockdown of CIP2A (mean

in their 5'UTR, such as G-quadruplexes structures or IRES elements, enhancing their translation in specific situations like tumor development [31]. The possibility that CIP2A regulates MYC translation via such a structure is promoted by our results showing a difference in translation efficacy dependent on the 5'UTR of MYC. The exact translation initiation factor which regulates CIP2A-dependent MYC translation in CRC is not known so far.

It has been shown that CIP2A regulates the phosphorylation of target proteins via inhibition of PP2A-mediated dephosphorylation [32]. So far, several studies have demonstrated that PP2A, besides the regulation of MYC via its dephosphorylation, is also able to function in mRNA translation. In lung fibroblasts, PP2A regulates 4E-BP1, the eIF4E inhibitor, by preventing its degradation and by this reducing CAPdependent translation [33]. In addition to 4E-BP1, PP2A directly influences the activity of eIF4E by dephosphorylating MNK1 and eIF4E at their activating phosphorylation sites, thereby reducing MYC and MCL-1 expression [34]. It is therefore possible that CIP2A regulates MYC mRNA translation indirectly via regulating the activity of the CAP-binding complex (Fig. 4c). Consistent with this hypothesis, it has been shown that the majority of CIP2A is localized in the cytoplasm rather than in the nucleus where it regulates the
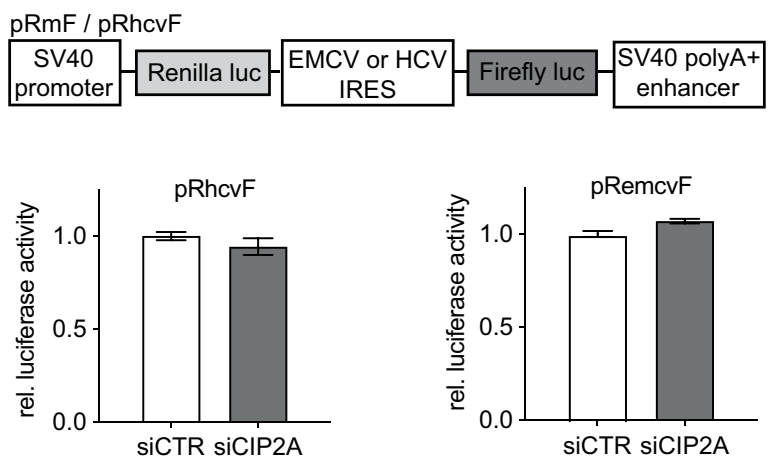

of three independent biological experiments, error bars represent $+/-\mathrm{SD}$ ). d HCT116 cells were transfected with MYC 5'UTR bearing pmF luciferase reporter and transfected with siCIP2A or siCTR (mean of three independent biological experiments, error bars represent $+/-\mathrm{SD} ; * p<$ 0.01). e HCT116 cells were transfected with bicistronic luciferase reporter vectors containing the HCV or EMCV IRES-element and transfected with siCIP2A or siCTR (mean of three independent biological experiments, error bars represent $+/-\mathrm{SD}$ )

association of MYC with the Lamin A/C complex and pS62-MYC stability [20].

Mounting evidence indicates that protein synthesis is deregulated in tumors in a way that in total, more and different mRNAs are translated compared to normal tissue [28, 35, 36]. In line with this, we show here that depletion of CIP2A specifically decreases translation of MYC.

In conclusion, we demonstrate a possible novel way of action of CIP2A controlling MYC expression specifically via regulation of MYC translation in CRC.

\section{Methods}

\section{Cell lines and cell culture}

HCT116, LS174t, and SW480 cells were purchased from American Type Culture Collection. All cell lines were authenticated via Short Tandem Repeat (STR) DNA analysis. HCT116 cells were cultured in DMEM, LS174t, and SW480 cells in RPMI-1640 medium supplemented with $10 \%$ heat-inactivated fetal calf serum (FCS) and $1 \%$ penicillin-streptomycin. Cells were cultured in an incubator at $37{ }^{\circ} \mathrm{C}$, 95\% humidity, and $5 \% \mathrm{CO}_{2}$. 


\section{a}

\begin{tabular}{|c|c|c|c|}
\hline & CDS MYC & HA-tag & \\
\hline 5 UTR & CDS MYC & HA-tag & \\
\hline & CDS MYC & HA-tag & 3'UTR \\
\hline 5'UTR & CDS MYC & HA-tag & 3'UTR \\
\hline
\end{tabular}

b
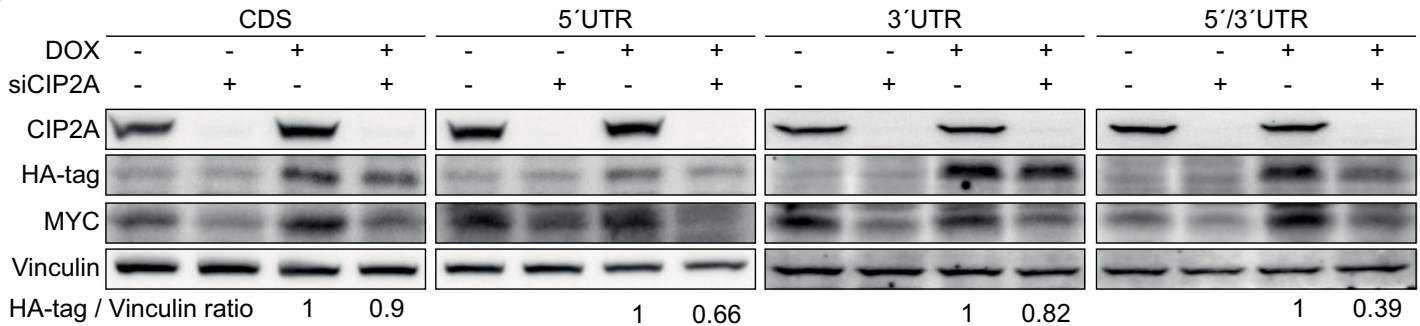

C

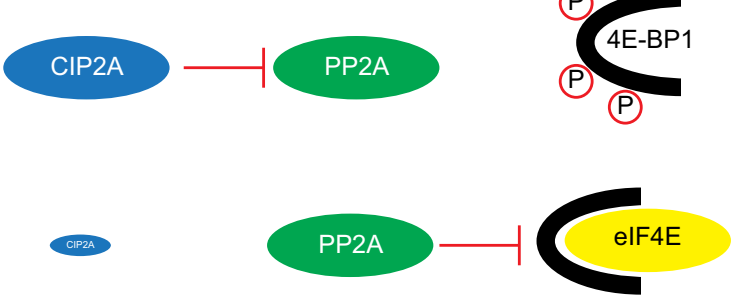

Fig. 4 CIP2A regulates MYC mRNA translation initiation. a Schematic illustration describing the MYC constructs used in B. b Western blot analysis of CIP2A, MYC, and HA-tag expression in HCT116 after

\section{Real-time quantitative reverse transcription-PCR analysis}

mRNA expression was analyzed using real-time quantitative reverse transcription-PCR (RT-QPCR). Total cellular RNA was extracted from cells with RNeasy Minikit (Qiagen) according to the manufacturer's instructions. Relative quantification, based on the fold difference, was calculated with the threshold cycle $(\mathrm{Ct})$ method, expressed as $2^{-\Delta \Delta \mathrm{Ct}}$.

\section{Immunoblot analysis}

Cultured cells were rinsed three times with ice-cold PBS, harvested, and lysed directly in RIPA sample buffer for western blot analysis. Cell debris were removed by centrifugation at $12,000 \mathrm{~g}$ for $10 \mathrm{~min}$ at $4{ }^{\circ} \mathrm{C}$, and the supernatant was used as total protein lysate. For each sample, $10 \mu \mathrm{g}$ of total protein lysate was subjected to a $10 \%$ sodium dodecyl sulfatepolyacrylamide gel electrophoresis (SDS-Page), followed by western blot analysis. Western blots were probed with antibodies against CIP2A (A301-454A; Bethyl Laboratories), MYC (C33, \#42; Santa Cruz; or Y69 \# ab32072 Abcam), $\beta$ actin (AC-15/A5441; Sigma), vinculin (V9131; Sigma), and HA-tag (HA-Tag; C29F4 \#3724S cell signaling). All

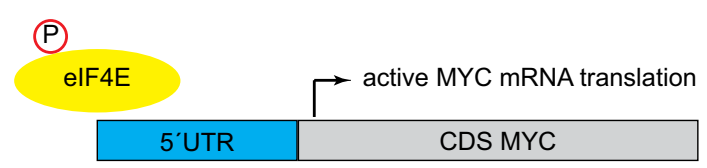

\begin{tabular}{|c|c|}
\multicolumn{1}{c}{} & Pinactive MYC mRNA translation \\
\hline 5 'UTR & CDS MYC \\
\hline
\end{tabular}

knockdown of CIP2A. Data are representative of three independent experiments. Every construct was evaluated on separate gels. c Summary of suggested molecular mechanism.

antibodies were used according to the manufacturer's instructions. The blots were visualized with secondary antibodies (GE Healthcare) against mouse (NA9310) or rabbit (NA9340) primary antibodies.

\section{siRNA transfection}

On-target plus SMART pool (Horizon Discovery) siRNA to target CIP2A (L-014135-01-005) and a control siRNA (D-001810-10-05) were used for silencing gene expression. Cells were transfected with siRNA pools (final concentration $100 \mathrm{nM}$ ) using RNAiMax kit (Invitrogen) according to the manufacturer's protocol. Cells were harvested $72 \mathrm{~h}$ after transfection.

\section{shRNA and lentivirus}

shRNA sequences targeting CIP2A were cloned into a lentiviral pGIPZ vector according to the manufacturer's protocol. HEK293t cells were transfected together with packaging plasmids. After $48 \mathrm{~h}$ and $72 \mathrm{~h}$, supernatants containing the virus were collected and filtered. Colon cancer cell lines were infected with the shCIP2A-expressing lentivirus or non- 
specific shCTR, and $24 \mathrm{~h}$ post-transduction infected cells were selected with puromycin.

\section{Colony formation assay}

$2.5 \times 10^{3}$ cells infected with shCIP2A-expressing lentivirus or shCTR were plated on 6-well plates. Colonies were stained with $0.5 \%$ cystal violet in $20 \%$ ethanol after 7 days in culture.

\section{Luciferase assay}

Plasmids and protocol for luciferase assay have previously been described in [37].

\section{$S^{35}$-Methionine incorporation assay}

Global translation was measured by $\mathrm{S}^{35}$-methionine incorporation assay. Cells were seeded in 6-well plates and treated as indicated. To deplete the intracellular pool of methionine, cells were washed with PBS and incubated in RPMI medium lacking methionine for $20 \mathrm{~min}$. Cells treated with $50 \mu \mathrm{g} / \mathrm{ml}$ cycloheximide were used as a control for translation inhibition. Cells were pulsed with $1 \mu \mathrm{Ci} / \mathrm{ml} \mathrm{S}^{35}$-methionine for $1 \mathrm{~h}$ at $37^{\circ} \mathrm{C}$. To remove unincorporated $\mathrm{S}^{35}$-methionine, cells were washed 5 times with ice-cold PBS prior to precipitation with $10 \%$ TCA for $20 \mathrm{~min}$. Cells were lysed with $300 \mu \mathrm{l} 0.2 \mathrm{M}$ $\mathrm{NaOH}$ and collected in a $1.5-\mathrm{ml}$ tube. Fifty-microliter cell lysate was added to $3-\mathrm{ml}$ scintillation solution in a scintillation tube and vortexed for $20 \mathrm{~s}$. Radioactive counts were measured by scintillation counting. Protein content in cell lysates was quantified using BCA reagent and used to normalize the radioactive counts.

Authors' contributions Conception and design: A. Wiegering, S. Schmidt, M. Eilers

Acquisition of data: A. Wiegering, Y. Schurr, G. Schwarz, S. Schote, S. Schmidt, C Armendariz, N. Matthes, F. Dejure, S. Denk

Analysis and interpretation of data: S. Denk, A. Wiegering, S.Schmidt, M. Eilers

Writing, review, and/or revision of the manuscript: A. Wiegering, S. Schmidt, S. Denk

Administrative, technical, or material support: A. Wiegering, M. Eilers All authors reviewed the manuscript.

Funding Open access funding enabled and organized by Projekt DEAL. AW: Interdisciplinary center for clinical research (IZKF B-186 and B-335); Else-Kröner-Fresenius Foundation (EKFS 2015_A57). This publication was funded by the German Research Foundation (DFG) and the University of Würzburg in the funding program Open Access Publishing.

\section{Compliance with ethical standards}

Conflict of interest The authors declare that they have no competing interests.
Open Access This article is licensed under a Creative Commons Attribution 4.0 International License, which permits use, sharing, adaptation, distribution and reproduction in any medium or format, as long as you give appropriate credit to the original author(s) and the source, provide a link to the Creative Commons licence, and indicate if changes were made. The images or other third party material in this article are included in the article's Creative Commons licence, unless indicated otherwise in a credit line to the material. If material is not included in the article's Creative Commons licence and your intended use is not permitted by statutory regulation or exceeds the permitted use, you will need to obtain permission directly from the copyright holder. To view a copy of this licence, visit http://creativecommons.org/licenses/by/4.0/.

\section{References}

1. Bray F, Ferlay J, Soerjomataram I, Siegel RL, Torre LA, Jemal A (2018) Global cancer statistics 2018: GLOBOCAN estimates of incidence and mortality worldwide for 36 cancers in 185 countries. CA Cancer J Clin. 68(6):394 424. Epub 2018/09/13. https://doi. org/10.3322/caac. 21492

2. Cancer Genome Atlas N (2012) Comprehensive molecular characterization of human colon and rectal cancer. Nature 487(7407): 330-337. https://doi.org/10.1038/nature11252

3. Sansom OJ, Meniel VS, Muncan V, Phesse TJ, Wilkins JA, Reed KR, Vass JK, Athineos D, Clevers H, Clarke AR (2007) Myc deletion rescues Apc deficiency in the small intestine. Nature. 446(7136):676-679. https://doi.org/10.1038/nature05674

4. Adhikary S, Eilers M (2005) Transcriptional regulation and transformation by Myc proteins. Nat Rev Mol Cell Biol. 6(8):635-645. https://doi.org/10.1038/nrm1703

5. Soofiyani SR, Hejazi MS, Baradaran B (2017) The role of CIP2A in cancer: a review and update. Biomed Pharmacother. 96:626633. https://doi.org/10.1016/j.biopha.2017.08.146

6. Junttila MR, Puustinen P, Niemela M, Ahola R, Arnold H, Bottzauw T et al (2007) CIP2A inhibits PP2A in human malignancies. Cell. 130(1):51-62. https://doi.org/10.1016/j.cell.2007.04.044

7. Wiegering A, Pfann C, Uthe FW, Otto C, Rycak L, Mader U et al (2013) CIP2A influences survival in colon cancer and is critical for maintaining Myc expression. PLoS One 8(10):e75292. https://doi. org/10.1371/journal.pone.0075292

8. Celikden SG, Baspinar S, Ozturk SA, Karaibrahimoglu A (2020) CIP2A expression in high grade prostatic intraepithelial neoplasia and prostate adenocarcinoma: a tissue microarray study. Malays $\mathbf{J}$ Pathol. 42(2):227-236

9. Khanna A, Bockelman C, Hemmes A, Junttila MR, Wiksten JP, Lundin M et al (2009) MYC-dependent regulation and prognostic role of CIP2A in gastric cancer. J Natl Cancer Inst. 101(11):793805. https://doi.org/10.1093/jnci/djp103

10. Bockelman C, Lassus H, Hemmes A, Leminen A, Westermarck J, Haglund $\mathrm{C}$ et al (2011) Prognostic role of CIP2A expression in serous ovarian cancer. Br J Cancer 105(7):989-995. https://doi. org/10.1038/bjc.2011.346

11. Ren J, Li W, Yan L, Jiao W, Tian S, Li D et al (2011) Expression of CIP2A in renal cell carcinomas correlates with tumour invasion, metastasis and patients' survival. Br J Cancer 105(12):19051911. https://doi.org/10.1038/bjc.2011.492

12. Come C, Laine A, Chanrion M, Edgren H, Mattila E, Liu X, Jonkers J, Ivaska J, Isola J, Darbon JM, Kallioniemi O, Thezenas S, Westermarck J (2009) CIP2A is associated with human breast cancer aggressivity. Clin Cancer Res. 15(16):5092-5100. https:// doi.org/10.1158/1078-0432.CCR-08-3283 
13. Chen W, Liang JL, Zhou K, Zeng QL, Ye JW, Huang MJ (2020) Effect of CIP2A and its mechanism of action in the malignant biological behavior of colorectal cancer. Cell Commun Signal 18(1):67

14. Birkman EM, Elzagheid A, Jokilehto T, Avoranta T, Korkeila E, Kulmala J et al (2018) Protein phosphatase 2A (PP2A) inhibitor CIP2A indicates resistance to radiotherapy in rectal cancer. Cancer Med 7(3):698-706

15. Zhao D, Liu Z, Ding J, Li W, Sun Y, Yu H, Zhou Y, Zeng J, Chen C, Jia J (2010) Helicobacter pylori CagA upregulation of CIP2A is dependent on the Src and MEK/ERK pathways. J Med Microbiol. 59(Pt 3):259-265. https://doi.org/10.1099/jmm.0.014704-0

16. Liu J, Wang X, Zhou G, Wang H, Xiang L, Cheng Y, Liu W, Wang Y, Jia J, Zhao W (2011) Cancerous inhibitor of protein phosphatase $2 \mathrm{~A}$ is overexpressed in cervical cancer and upregulated by human papillomavirus 16 E7 oncoprotein. Gynecol Oncol. 122(2):430436. https://doi.org/10.1016/j.ygyno.2011.04.031

17. Janssens V, Goris J (2001) Protein phosphatase 2A: a highly regulated family of serine/threonine phosphatases implicated in cell growth and signalling. Biochem J 353(Pt 3):417-439

18. Khanna A, Pimanda JE, Westermarck J (2013) Cancerous inhibitor of protein phosphatase $2 \mathrm{~A}$, an emerging human oncoprotein and a potential cancer therapy target. Cancer Res. 73(22):6548-6553. https://doi.org/10.1158/0008-5472.CAN-13-1994

19. Puustinen P, Rytter A, Mortensen M, Kohonen P, Moreira JM, Jaattela M (2014) CIP2A oncoprotein controls cell growth and autophagy through mTORC1 activation. J Cell Biol 204(5):713727. https://doi.org/10.1083/jcb.201304012

20. Myant K, Qiao X, Halonen T, Come C, Laine A, Janghorban M et al (2015) Serine 62-phosphorylated MYC associates with nuclear lamins and its regulation by CIP2A is essential for regenerative proliferation. Cell Rep 12(6):1019-1031. https://doi.org/10.1016/j. celrep.2015.07.003

21. Wiegering A, Uthe FW, Jamieson T, Ruoss Y, Huttenrauch M, Kuspert $M$ et al (2015) Targeting translation initiation bypasses signaling crosstalk mechanisms that maintain high MYC levels in colorectal cancer. Cancer Discov 5(7):768-781. https://doi.org/10. 1158/2159-8290.CD-14-1040

22. Dejure FR, Royla N, Herold S, Kalb J, Walz S, Ade CP et al (2017) The MYC mRNA 3'-UTR couples RNA polymerase II function to glutamine and ribonucleotide levels. EMBO J 36(13):1854-1868. https://doi.org/10.15252/embj.201796662

23. Bernard S, Eilers M (2006) Control of cell proliferation and growth by Myc proteins. Results Probl Cell Differ. 42:329-342

24. Farrell AS, Sears RC (2014) MYC degradation. Cold Spring Harb Perspect Med 4(3). https://doi.org/10.1101/cshperspect.a014365

25. Adhikary S, Marinoni F, Hock A, Hulleman E, Popov N, Beier R, Bernard S, Quarto M, Capra M, Goettig S, Kogel U, Scheffner M, Helin K, Eilers M (2005) The ubiquitin ligase HectH9 regulates transcriptional activation by Myc and is essential for tumor cell proliferation. Cell. 123(3):409-421. https://doi.org/10.1016/j.cell. 2005.08.016

26. Peter S, Bultinck J, Myant K, Jaenicke LA, Walz S, Muller J et al (2014) Tumor cell-specific inhibition of MYC function using small molecule inhibitors of the HUWE1 ubiquitin ligase. EMBO Mol
Med 6(12):1525-1541. https://doi.org/10.15252/emmm. 201403927

27. Schmidt S, Denk S, Wiegering A (2020) Targeting protein synthesis in colorectal cancer. Cancers (Basel) 12(5). https://doi.org/10. 3390/cancers 12051298

28. Schmidt S, Gay D, Uthe FW, Denk S, Paauwe M, Matthes N, Diefenbacher ME, Bryson S, Warrander FC, Erhard F, Ade CP, Baluapuri A, Walz S, Jackstadt R, Ford C, Vlachogiannis G, Valeri N, Otto C, Schülein-Völk C, Maurus K, Schmitz W, Knight JRP, Wolf E, Strathdee D, Schulze A, Germer CT, Rosenwald A, Sansom OJ, Eilers M, Wiegering A (2019) A MYC-GCN2-eIF2alpha negative feedback loop limits protein synthesis to prevent MYC-dependent apoptosis in colorectal cancer. Nat Cell Biol. 21:1413-1424. https://doi.org/10.1038/s41556-0190408-0

29. Laine A, Sihto H, Come C, Rosenfeldt MT, Zwolinska A, Niemela $M$ et al (2013) Senescence sensitivity of breast cancer cells is defined by positive feedback loop between CIP2A and E2F1. Cancer Discov 3(2):182-197. https://doi.org/10.1158/2159-8290.CD-120292

30. Huang CY, Wei CC, Chen KC, Chen HJ, Cheng AL, Chen KF (2012) Bortezomib enhances radiation-induced apoptosis in solid tumors by inhibiting CIP2A. Cancer Lett. 317(1):9-15. https://doi. org/10.1016/j.canlet.2011.11.005

31. Wolfe AL, Singh K, Zhong Y, Drewe P, Rajasekhar VK, Sanghvi VR et al (2014) RNA G-quadruplexes cause eIF4A-dependent oncogene translation in cancer. Nature 513(7516):65-70. https://doi. org/10.1038/nature13485

32. Remmerie M, Janssens V (2019) PP2A: A promising biomarker and therapeutic target in endometrial cancer. Front Oncol 9:462. https://doi.org/10.3389/fonc.2019.00462

33. Nho RS, Peterson M (2011) Eukaryotic translation initiation factor $4 \mathrm{E}$ binding protein 1 (4EBP-1) function is suppressed by Src and protein phosphatase 2A (PP2A) on extracellular matrix. J Biol Chem. 286(37):31953-31965. https://doi.org/10.1074/jbc.M111. 222299

34. Li Y, Yue P, Deng X, Ueda T, Fukunaga R, Khuri FR et al (2010) Protein phosphatase $2 \mathrm{~A}$ negatively regulates eukaryotic initiation factor 4E phosphorylation and eIF4F assembly through direct dephosphorylation of Mnk and eIF4E. Neoplasia. 12(10):848-855

35. Bhat M, Robichaud N, Hulea L, Sonenberg N, Pelletier J, Topisirovic I (2015) Targeting the translation machinery in cancer. Nat Rev Drug Discov. 14(4):261-278. https://doi.org/10.1038/ $\operatorname{nrd} 4505$

36. Truitt ML, Ruggero D (2016) New frontiers in translational control of the cancer genome. Nat Rev Cancer. 16(5):288-304. https://doi. org/10.1038/nrc.2016.27

37. Cobbold LC, Spriggs KA, Haines SJ, Dobbyn HC, Hayes C, de Moor $\mathrm{CH}$ et al (2008) Identification of internal ribosome entry segment (IRES)-trans-acting factors for the Myc family of IRESs. Mol Cell Biol 28(1):40-49. https://doi.org/10.1128/MCB.0129807

Publisher's note Springer Nature remains neutral with regard to jurisdictional claims in published maps and institutional affiliations. 